Document downloaded from:

http://hdl.handle.net/10251/119616

This paper must be cited as:

Font-Pérez, A.; Borrachero Rosado, MV.; Soriano Martinez, L.; Monzó Balbuena, JM.; Mellado Romero, AM.; Paya Bernabeu, JJ. (2018). New eco-cellular concretes: sustainable and energy-efficient material. Green Chemistry. 20:4684-4694.

https://doi.org/10.1039/c8gc02066c

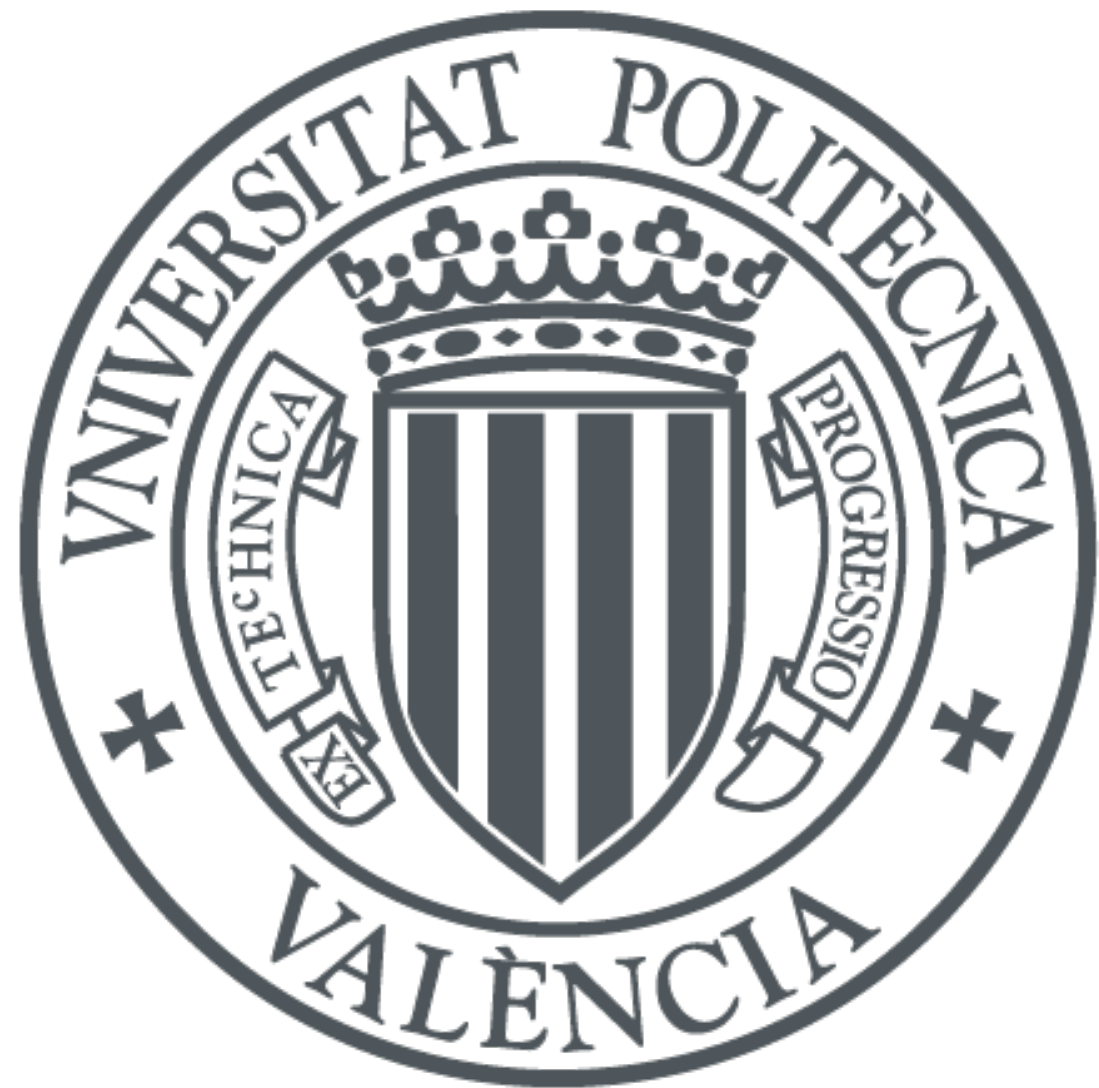

The final publication is available at

http://doi.org/10.1039/c8gc02066c

Copyright The Royal Society of Chemistry

Additional Information 


\title{
NEW ECO-CELLULAR CONCRETES: SUSTAINABLE AND ENERGY-EFFICIENT
} MATERIAL

\author{
Alba Font, María Victoria Borrachero, Lourdes Soriano, José Monzó, Ana Mellado, Jordi Payá
}

\author{
ICITECH - Instituto de Ciencia y Tecnología del Hormigón, Grupo de Investigación en
}

Química de los Materiales (GIQUIMA), Universitat Politècnica de València, València, Spain.

\author{
* Corresponding author: jjpaya@cst.upv.es; Tel.: +34 963877564
}

\begin{abstract}
Chemistry is an essential science for understanding and developing construction materials. Specifically, the application of the green chemistry concept to the cement sector might allow the fabrication of new environmentally friendly materials in sustainability and energy efficiency terms. Cellular concretes are an excellent alternative to conventional concrete in thermal insulation and material saving terms. In this paper the development of waste-based cellular concrete is presented bearing out its good performance and the focus of their low environmental impact is warrantied. Three different cellular concrete systems were investigated: i) traditional cellular concrete based on ordinary Portland cement and commercial aluminium powder; ii) geopolymer cellular concrete applying the alkali activated chemical technology, by comparing the use of two precursors, fluid catalytic cracking catalyst residue (FCC) and blast furnace slag (BFS) as precursors, and recycled aluminium foil as an aerating agent; iii) eco-cellular concrete, where commercial waterglass was replaced by an agro-industrial by-product, rice husk ash (RHA), in the activating solution. The development of geopolymer cellular concrete with different precursors and activating solutions have proven that the production of this type of concrete by using different nature precursors and in several availability context is enabled depend of the by-products and wastes availability. The density, compressive strength, and thermal properties of the three cellular concrete systems were assessed and a complete study on the carbon footprint of the developed concretes is presented. The results show alternative concretes with densities from 474 to $813 \mathrm{~kg} / \mathrm{m}^{3}$, with compressive strength from 2.6 to $4.6 \mathrm{MPa}$, and with thermal conductivities from 0.083 to $0.281 \mathrm{~W} / \mathrm{mK}$. In the case of the cellular concrete prepared by using RHA in the activating reagent, the heat released from dissolution of $\mathrm{NaOH}$ pellets in water dissolve the soluble silica present in the ash. The production implied a reduction of which carbon footprint by $78 \%$.
\end{abstract}




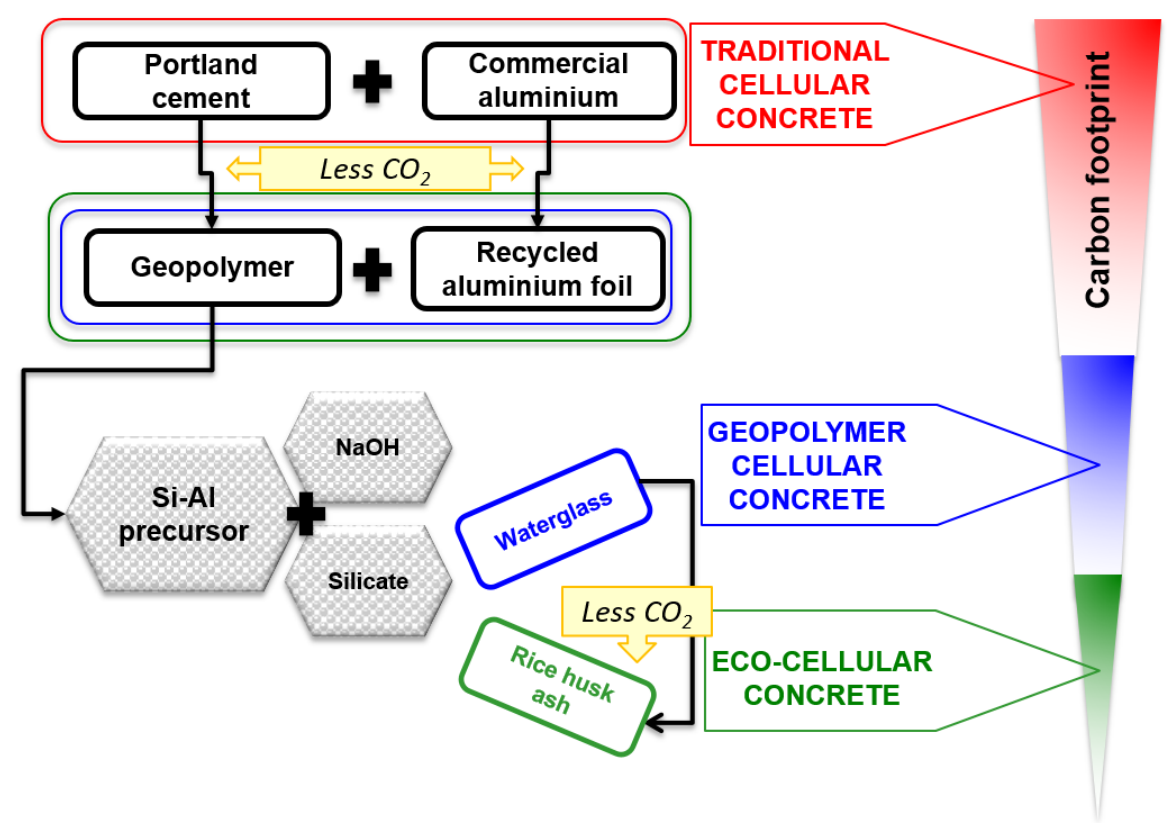

\section{Acronyms}

OPC: Ordinary Portland cement

A: Commercial aluminium powder

FCC: Fluid catalytic cracking catalyst residue

BFS: Blast furnace slag

RAF: Recycled aluminium foil

RHA: Rice husk ash

TCC: Traditional cellular concrete (OPC + commercial aluminium powder: OPCA)

GCC: Geopolymer cellular concrete: co-milling of precursor and recycled aluminium foil (RAF):

- FCCRm: Solid resulted of the co-milling of FCC and RAF

- $\quad$ FR samples: Material resulted of blending FCCRm with the conventional activating solution

- $\quad$ BFSRm: solid resulted of the co-milling of BFS and RAF

- $\quad$ SR samples: Material resulted of blending BFSRm with the conventional activating solution

ECC: Eco-cellular concrete: use the RHA as silica source in activating solution (alternative activating solution):

- FRR samples: Material resulted of blending FCCRm with alternative activating solution

- SRR samples: Material resulted of blending BFSRm with alternative activating solution 


\section{INTRODUCTION}

Nowadays, $50 \%$ of total $\mathrm{CO}_{2}$ emissions, $40 \%$ of used primary power and $75 \%$ of electric power generation come from the building industry ${ }^{1,2}$. Construction materials are an important factor of these consumptions and conventional concrete is the most widely used material in this industry ${ }^{3}$. The use of this material structurally goes beyond requirements in most situations.

Cellular concrete can be an environmentally friendly material with great insulation and low density properties $^{4}\left(300-1800 \mathrm{~kg} / \mathrm{m}^{3}\right.$ ) that yields moderate mechanical behavior ${ }^{5}$. It is an ordinary Portland cement (OPC) based material prepared by mixing with water, and occasionally with fine aggregates (sand or lightweight aggregates), with an internal air-void system formed by the addition of suitable reagents. There are two methods to introduce air into the matrix: a chemical reaction in the alkaline medium of metal powders (aerated concrete) or foam introduced with a surfactant addition (foamed concrete $)^{6}$. The combination of these methods has been recently studied to improve a suitable porous structure ${ }^{7}$.

The addition of metallic aluminium powder is the most widespread method employed for air-bubbles entrapping in traditional cellular concretes (TCC) ${ }^{8}$. This reagent is oxidised in an OPC alkaline medium, where it comes in contact with the mixing water and the produced $\mathrm{H}_{2}$ gas, as shown in Equation (1).

$$
2 \mathrm{Al}+3 \mathrm{Ca}(\mathrm{OH})_{2}+6 \mathrm{H}_{2} \mathrm{O} \Rightarrow 3 \mathrm{CaO} \cdot \mathrm{Al}_{2} \mathrm{O}_{3} \cdot 6 \mathrm{H}_{2} \mathrm{O}+3 \mathrm{H}_{2}
$$

For many applications, TCC can provide cost and performance benefits compared with traditional construction materials. As this material combines insulation properties and structural capability, it is excellent for walls, floors and roofs, and its cost is sufficiently competitive with brick, wood and other materials costs ${ }^{9}$. Furthermore, TCC is easy to cut, shape and size, and it readily takes nails or screws. Common TCC applications are: pre-cast lightweight blocks, cast in situ lightweight walls, roof and floor insulation screeds, void-filling, ground stabilisation, geotechnical and mine fill applications, and roads on soft grounds ${ }^{9-11}$.

Thus TCC are an excellent alternative to conventional concrete in several structural situations. Even so its components are actually responsible for major environmental and energetic impacts.

The ordinary Portland cement represents nearly 70\% (by wt) of total TCC constituents (as opposed to $11 \%$ in conventional concrete), and the impact of this binder is well-known in terms of energy demand, non renewable materials and the $\mathrm{CO}_{2}$ footprint ${ }^{12,13}$. From a chemical point of view, the application of the alkali activation aiming the OPC replacement, are commonly studied as a cleaner alternative ${ }^{14-16}$. The alkali-activated cements or geopolymers consist of two essential components: a precursor, a mineral silico-aluminate raw material, rather amorphous or vitreous; and an alkali activator, a high concentrated aqueous dissolution of alkali compounds (hydroxides, silicates). The geopolymerization calls for inorganic polycondensation reaction, which results in three-dimensional zeolitic frameworks ${ }^{17}$. For this hardening (setting) mechanism, the first step is the precursor dissolution in contact with the $\mathrm{OH}^{-}$groups (that involves a high alkaline medium). The $\mathrm{Al}$ and $\mathrm{Si}$ ion are diffused or transported from the particle surface inward, giving rise to a gel-like phase. And finally, a rigid chains or series of intertwined tetrahedral joined by oxygen atoms are developed (species polycondensation), which must have alkaline cations enough to offset the charge from the tetra-coordinated aluminium. The result is a well-stabilised, stable and insoluble geopolymer binder.

The mineral precursor may be a synthetized product, such as metakaolin (MK), or an industrial waste, such as fluid catalytic cracking catalyst residue (FCC), fly ash or blast furnace slag (BFS). Depending on the calcium content in the precursor, they can be classified according to the nature of the reaction product: i) precursors with low calcium content (Equation (2)) reacts to form alumino-silicate hydrate gel (NASH); and ii) precursors with high calcium content ( $\mathrm{CaO}>30 \%$, Equation (3)) reacts to form calcium alumino-silicate hydrate gel (CASH). 


$$
\text { Precursor }+(\mathrm{Na}, \mathrm{K}) \mathrm{OH} \text { or }(\mathrm{Na}, \mathrm{K})_{2} \mathrm{SiO}_{3}+\mathrm{H}_{2} \mathrm{O} \rightarrow(\mathrm{Na}, \mathrm{K})_{2} \mathrm{O}-\mathrm{Al}_{2} \mathrm{O}_{3}-\mathrm{SiO}_{2}-\mathrm{H}_{2} \mathrm{O} \text { (NASH gel) }
$$

$$
\text { Precursor }+(\mathrm{Na}, \mathrm{K}) \mathrm{OH} \text { or }(\mathrm{Na}, \mathrm{K})_{2} \mathrm{SiO}_{3}+\mathrm{H}_{2} \mathrm{O} \rightarrow\left((\mathrm{Na}, \mathrm{K})_{2} \mathrm{O}-\mathrm{CaO}-\mathrm{Al}_{2} \mathrm{O}_{3}-\mathrm{SiO}_{2}-\mathrm{H}_{2} \mathrm{O}(\mathrm{CASH} \text { gel })\right.
$$

The applications of geopolymer systems in manufacturing cellular concretes have emerged as a novel lightweight insulation material ${ }^{6}$. In the geopolymer system for cellular concrete manufacture the strongly alkaline medium make effective the aluminium oxidation thus ensuring hydrogen release as shown in Equation (4). Recent research has focused on studying these new materials. The use of BFS as a precursor to produce cellular concretes has been reported by Esmaily et al. ${ }^{7}$ where aluminium powder aeration was combined with the sodium lauril sulphate foaming effect. Besides, Font et al. ${ }^{18}$ have recently tested FCC as a precursor in cellular concrete aerated by using recycled aluminium foil. Both of these studies obtained excellent results thanks to their easy production and good performance without any autoclave curing process requirement.

$$
\mathrm{Al}(\mathrm{s})+3 \mathrm{H}_{2} \mathrm{O}+\mathrm{OH}_{(\mathrm{ac})}^{-} \Rightarrow \mathrm{Al}(\mathrm{OH})_{4}^{-}(a c)+3 / 2 \mathrm{H}_{2}(\mathrm{~g})
$$

The alkali solution commonly used for geopolymer activation requires silicates to obtain goodperforming materials, thus the $\mathrm{SiO}_{4}{ }^{4-}$ anion favours the formation of a denser and stronger structure ${ }^{19}$. By its important reactive part of silica, the commercial waterglass (WG) is the most common chemical reagent utilised, combined with $\mathrm{NaOH} /$ water solution. Nevertheless the WG is expensive (20 \% of total cost of alkali activated cement production) and this synthesis represent a higher greenhouse gas emitter process ( $50-70 \%$ of total emissions of alkali activated cements constituents $)^{20}$. The sodium silicate production consists on the melting of silica $\left(\mathrm{SiO}_{2}\right)$ and sodium carbonate $\left(\mathrm{Na}_{2} \mathrm{CO}_{3}\right)$ until $1400^{\circ} \mathrm{C}^{21}$, releasing a large amount of $\mathrm{CO}_{2}$ (Equation (5)). For this reason, studying alternatives to replace this silica source has become the next "must have" in recent years ${ }^{22}$, and rice husk ash (RHA) ${ }^{23}$, sugar cane straw ash (SCSA) $)^{24}$ and glass waste ${ }^{25}(\mathrm{GW})$ have been recently investigated.

$$
\mathrm{x} \mathrm{Na}_{2} \mathrm{CO}_{3}(\mathrm{~s})+\mathrm{y} \mathrm{SiO} 2(\mathrm{~s}) \rightarrow\left(\mathrm{Na}_{2} \mathrm{O}\right)_{\mathrm{x}}\left(\mathrm{SiO}_{2}\right)_{\mathrm{y}}(\mathrm{s})+\mathrm{x} \mathrm{CO}_{2} \uparrow(\mathrm{g})
$$

Near 471 million tones of rice were produced in 2014 which the hull represents $20 \%$ by weight ${ }^{26}$. The rice hull is removed and is burned to their volume reduce for disposal. This RHA contains $65-90 \% \mathrm{wt}$ $\%$ amorphous $\mathrm{SiO}_{2}{ }^{27}$. The appropriate management of rice husk and their ashes becomes an important environmental aspect because the contamination produced in farmland and watercourses in agricultural regions. The high silica content in rice husk ashes may allows their use in the new alternative geopolymer binders by its solubilisation in the activating solution yielding important environmental as well as economic profits. Recently, the use of RHA as a silica source in one-part slag alkali activated binders was introduced ${ }^{28}$. These binders consist on the mix of the precursor with the solid alkali activator and water is added to initiate the reaction.

Another high environmental and economic impact of TCC is caused by aluminium powder manufacturing. To obtain one tonne of pure aluminium from bauxite, $15000 \mathrm{kWh}$ of heat generated by electric energy is required and five tons of residues are produced ${ }^{29,30}$. Apart from this, there is the additional major contribution of treatment subsequent to powder manufacturing by stamp milling, ball milling under dry conditions, wet ball milling, attrition milling and vibration milling. Since aluminium never loses its performance or strength during the recycling process, the same piece of aluminium can enter the secondary production process time and time again, which multiplies cost savings and environmental benefits. Furthermore, recycling aluminium achieves up to $95 \%$ of energy savings compared to the energy required to manufacture the same amount of aluminium to avoid depletion in 
bauxite extraction. The result is a reduction in power from $21 \mathrm{kWh}$ in the 1950 s to $14 \mathrm{kWh}$ in 1997 for $1 \mathrm{~kg}$ of manufactured aluminium ${ }^{31}$.

The use of alternative sources of aluminium to TCC aeration have been investigated by Araujo et al. ${ }^{32}$ by incorporating aluminium recycled scrap powders. As a result, cellular concrete blocks with densities less than $500 \mathrm{~kg} / \mathrm{m}^{3}$ and low compressive strength (1.5 MPa) were obtained by an autoclaved curing treatment $\left(200^{\circ} \mathrm{C}\right.$ and $\left.10 \mathrm{~atm}\right)$. These authors concluded that milling time, oxidation level and addition of hard particles are the parameters that control the required density and strength properties.

Recycled domestic foil is another interesting alternative to use as a reagent. Annually in Europe, close to 860000 tons of aluminium foil are produced, which represents a mean use of more than $26 \mathrm{~m}^{2}$ per habitant $^{33}$. The inclusion of recycled foil in the milling procedure of FCC has been recently tested by Font et al. ${ }^{18}$ to use it as a raw material in new geopolymer cellular concrete (GCC) manufacturing. These GCC offer several advantages over traditional OPC-based cellular concretes in terms of natural densities, air-void distribution and thermal conductivity.

\section{OBJECTIVE}

In the present paper three steps to improve the sustainability and energy-efficiency landscape of TCC are introduced, combined and discussed: i) developing a geopolymer system by using both FCC and BFS as alternative precursors to replace OPC; ii) using recycled aluminium foil (RAF) to replace commercial aluminium powder (A); iii) producing the activating solution by using rice husk ash (RHA) as an alternative silica source for replacing commercial waterglass (WG).

The study of two precursors with different nature (high calcium vs. low calcium content) is essential to test the material reproducibility depending on the manufacture context and resources availability. The fluid catalytic cracking residue (FCC) is a low calcium content precursor whose potential as geopolymer precursor was proved by Tashima et.al (2012). On the other hand, the blast furnace slag (BFS) is a high calcium precursor and $\mathrm{CaO} / \mathrm{SiO}_{2}$ molar ratio between 0.1 and 0.6 are considered suitable for alkaline activation [Talling and Brasdstetr 1989). The FCC was selected to continue the previous work [Font 17] where the precursor was mixed with RAF using a conventional alkali solution ( $\mathrm{NaOH}+$ water $+\mathrm{WG}$ ). In the case of BFS there is no previous works where cellular concrete of this activated precursor was aereated by RAF addition.

Natural density, mechanical behaviour and thermal insulation must be assessed and controlled to obtain good-performing cellular concretes. Thus the proposed materials were tested to verify its resultant behaviour.

The aim of the present investigation is the new eco-cellular concrete development, which yields good performance and represents a potential solution front the traditional cellular concrete in terms of environmental and energy-saving impacts (measured as carbon footprint assessment).

\section{EXPERIMENTAL}

\subsection{Materials}

In Table 1 an overview of the material composition of each mixture assessed in this study is shown. Three cellular concrete systems were fabricated, tested and compared:

i. $\quad$ Traditional cellular concrete (TCC), which consists in a traditional cellular system based on OPC aerated by commercial aluminium powder (A). These two materials were drymixed manually for 1 minute to homogenise, and the mix was used as raw material (OPCA) to reference material manufacture (CA).

ii. Two geopolymer cellular concretes (GCCs), designed by employing the dry solid resulting from the co-milling of the precursor with recycled aluminium foil (RAF) as the raw material: a) FCC with RAF (hereafter called FCCRm); and b) BFS with RAF (hereafter called BFSRm). The activation of each precursor (FCC or BFS) was by using an alkali solution made from sodium hydroxide and commercial waterglass (NaOH/WG). 
iii. Two eco-cellular concretes (ECCs), prepared with the same raw material combinations as GCCs (FCCRm and BFSRm), where in the alkali solution the commercial waterglass was replaced with an alternative source of active silica, the rice husk ash (RHA). 
Table 1 Overview of dosages.

\begin{tabular}{|c|c|c|c|c|c|c|}
\hline \multirow[b]{3}{*}{ TCC } & \multirow{3}{*}{$\begin{array}{c}\text { Mixtures } \\
\text { CA }\end{array}$} & \multicolumn{4}{|c|}{ Solid phase } & \multirow[t]{2}{*}{ Liquid phase } \\
\hline & & Precursor & $\begin{array}{l}\text { Aluminium } \\
\text { type }\end{array}$ & $\begin{array}{c}\text { Pre- } \\
\text { treatment }\end{array}$ & $\begin{array}{c}\text { Raw material } \\
\text { designation }\end{array}$ & \\
\hline & & OPC & A & Dry mix & OPCA & Water \\
\hline \multirow{2}{*}{ GCC } & FR & FCC & \multirow{4}{*}{ RAF } & \multirow{4}{*}{ Co-milling } & FCCRm & \\
\hline & SR & BFS & & & BFSRm & \\
\hline \multirow{2}{*}{ ECC } & FRR & FCC & & & FCCRm & \multirow{2}{*}{$\mathrm{NaOH}+\mathrm{RHA}$} \\
\hline & SRR & BFS & & & BFSRm & \\
\hline
\end{tabular}

OPC (CEM I 52.5R) was supplied by Lafarge S.A (Puerto de Sagunto, Spain). Fluid catalytic cracking catalyst residue (FCC) was supplied by the BP Oil Company (Grao de Castellón, Spain) and blast furnace slag (BFS) was supplied as large grains by Cementval S.A (Puerto de Sagunto, Spain). The chemical compositions of OPC, FCC and BFS are summarized in Table 2.

Commercial aluminium powder (A) was supplied by Schlenk Metallic Pigments GmbH, whose mean particle diameter was $30 \mu \mathrm{m}$ and the recycled aluminium foil (RAF), was supplied by the Department of Agricultural Forest Ecosystems at the Universitat Politècnica de València (Valencia, Spain). RAF was recycled after using it to cover crop glass containers in autoclaving treatments. FCC and BFS required a previous milling treatment to obtain a fine material to be used as a solid precursor ${ }^{34,35}$. As previously demonstrated $^{18}$ the method to incorporate RAF into the paste matrix to allow optimal reaction performance is done by blending RFA (previously reduced in small sheets: $35 \mathrm{~mm}$ long, $4 \mathrm{~mm}$ wide) in the FCC milling process. FCC and RAF sheets (0.2\% wt\%) were milled in a ball mill for 20 minutes to obtain a new raw material for cellular concrete manufacturing, which was designated as FCCRm (Table 1). Its mean particle diameter ( $\left.D_{\text {mean }}\right)$ was $18.43 \mu \mathrm{m}$. BFS and RAF sheets $(0.2 \% \mathrm{wt} \%)$ were milled in a ball mill for 30 minutes to obtain a new raw material for cellular concrete manufacturing, which was designated as BFSRm (Table 1). Its mean particle diameter ( $\left.\mathrm{D}_{\text {mean }}\right)$ was $26.28 \mu \mathrm{m}$.

To prepare the activating solutions, the following chemical reagents were used: i) sodium hydroxide $(\mathrm{NaOH})$ in the form of pellets (98\% purity), acquired from Panreac S.A; ii) commercial sodium silicate (or commercial waterglass - WG), supplied by Merck-Spain (8 wt $\% \mathrm{Na}_{2} \mathrm{O}, 28 \% \mathrm{wt} \% \mathrm{SiO}_{2}$ and $64 \%$ wt $\%$ $\mathrm{H}_{2} \mathrm{O}$ ). Finally, rice husk ash (RHA) was utilised as an alternative silica source to produce the activating solution. This ash was supplied by DACSA S.A (Tabernes Blanques, Spain). RHA is composed mainly of $\mathrm{SiO}_{2}$ (85.6 wt\%), as seen in Table 2, and was used without milling ( $\mathrm{D}_{\text {mean }}$ of $62.3 \mu \mathrm{m}$ ) because the particle diameter did not influence on the mechanical properties of geopolymers, as was reported by Bouzón et al. ${ }^{23}$.

Table 2 Chemical compositions of OPC, FCC, BFS and RHA (wt\%).

\begin{tabular}{ccccccccccccc}
\hline & $\mathrm{SiO}_{2}$ & $\mathrm{Al}_{2} \mathrm{O}_{3}$ & $\mathrm{Fe}_{2} \mathrm{O}_{3}$ & $\mathrm{CaO}$ & $\mathrm{MgO}$ & $\mathrm{SO}_{3}$ & $\mathrm{~K}_{2} \mathrm{O}$ & $\mathrm{Na}_{2} \mathrm{O}$ & $\mathrm{P}_{2} \mathrm{O}_{5}$ & $\mathrm{TiO}_{2}$ & $\mathrm{Cl}$ & $\mathrm{LOI}^{*}$ \\
\hline OPC & 20.80 & 4.60 & 4.80 & 65.60 & 1.20 & 1.70 & 1.00 & 0.07 & - & - & - & 0.23 \\
\hline FCC & 47.76 & 49.26 & 0.60 & 0.11 & 0.17 & 0.02 & 0.02 & 0.31 & 0.01 & 1.22 & - & 0.53
\end{tabular}




\begin{tabular}{lllllllllllll} 
BFS & 30.53 & 10.55 & 1.29 & 40.15 & 7.43 & 1.93 & 0.57 & 0.87 & 0.26 & 0.89 & - & 5.53 \\
\hline RHA & 85.58 & 0.25 & 0.21 & 1.83 & 0.5 & 0.26 & 3.39 & - & 0.67 & - & 0.32 & 6.99 \\
\hline
\end{tabular}

*Loss on ignition

\subsection{Methods}

The experimental planning of this research was divided into two phases:

- $\quad$ First, the GCC and ECC mixes were prepared and tested by comparing the results with those obtained for the control samples of TCC. Density, compressive strength and thermal conductivity were studied.

- Secondly, calculation of the carbon footprint attributed to these GCCs and ECCs compared to TCC.

\section{Samples mixing and testing}

In this study, to the air bubble generation in the cellular concrete matrix (TCC, GCC and ECC), aluminium powder (A or RAF in each case) was added at $0.2 \%$ by weight of the solid precursor (OPC, FCC or BFS). This reagent percentage has been commonly tested by several authors ${ }^{36}$, which allows traditional cellular concrete with excellent physical and mechanical performances to be obtained. For the liquid phase, to gain an appropriate viscosity for good air-void development, the water/binder (w/b) ratio was selected $\mathrm{f}$ mixture. This ratio was: i) w/b $=0.5$ for the TCC system (CA samples); ii) w/b $=0.6$ for the FR mixes and w/b $=0.7$ for the FRR mixes; iii) $w / b=0.35$ and $w / b=0.45$ for the SR and the SRR mixes, respectively. In the geopolymer systems, the alkali activator solution parameters that determine the amount of $\mathrm{NaOH}$ and silica (WG in GCC or RHA in ECC) remained constant as follows: the $\mathrm{Na}^{+}$ molality was 7.5 and the $\mathrm{SiO}_{2} / \mathrm{Na}_{2} \mathrm{O}$ molar ratio was 1.7 . These parameters have been previously studied by Payá et al. ${ }^{37}$ and Bouzón et al., ${ }^{23}$ and were applied to GCC based on FCC by Font et al. ${ }^{18}$. The dosages for the samples based on BFS were maintained at the same proportions to make their physical and mechanical properties comparable, and in carbon footprint calculation terms. To prepare the alkaline solution, for GCC systems, $\mathrm{NaOH}$ and WG were mixed with water, and rest in a plastic beaker sealed with plastic film until room temperature was reached. For ECC, $\mathrm{NaOH}$ and $\mathrm{RHA}$ were mixed with water in a thermal bottle for 1 minute. To improve the solubilisation of silica in RHA by the heat released from the $\mathrm{NaOH}$ dissolution in water (according to Equation (6)), the thermal bottle was rest during 24 hours.

$$
2 \mathrm{x} \mathrm{NaOH}(\mathrm{s})+\mathrm{y} \mathrm{SiO} 2(\mathrm{~s})+\mathrm{n} \mathrm{H}_{2} \mathrm{O} \rightarrow\left(\mathrm{Na}_{2} \mathrm{O}\right)_{\mathrm{x}}\left(\mathrm{SiO}_{2}\right)_{\mathrm{y}}\left(\mathrm{H}_{2} \mathrm{O}\right)_{\mathrm{n}+\mathrm{x}} \text { (solution) }
$$

An AEG SBE705RE power drill connected to a paint mixer was used for sample preparation. For the cellular concrete manufacturing, the solid was mixed with its respective liquid phase (water for TCC or alkaline reagent for GCC and ECC) for 190 seconds in the TCC mixes and for 30 seconds for the dissolution, plus 90 seconds when the solid blend was incorporated into the GCC and ECC mixes (the total mixing time was 120 seconds). The alkali activated systems required a shorter mixing time because the high alkalinity medium provided a quick aluminium powder reaction compared to OPC systems. No compacting treatment was carried out to avoid gas escaping from the aerated concrete during the setting process. For each resulting concrete twelve $10 \times 10 \times 10 \mathrm{~cm}^{3}$ cube specimens were moulded and cured at $23^{\circ} \mathrm{C}$ and $100 \% \mathrm{RH}$ for $24 \mathrm{~h}$ when the free surface of cubes had to be cut with a saw blade. Then specimens were demoulded and kept in a wet chamber $\left(23^{\circ} \mathrm{C}\right.$ and $\left.100 \% \mathrm{RH}\right)$ until testing.

By considering natural density ( $\rho$ ) to be the volumetric mass density (mass per unit volume), it was determined by means of the weight of the 10 -cm cubic samples before compressive strength testing. The compressive strengths of the cellular concretes were obtained by an INSTRON 3282 universal testing machine. The compressive test was performed after 7 and 28 curing days. Tests were carried out on four cubic specimens $\left(10 \times 10 \times 10 \mathrm{~cm}^{3}\right)$ for each curing time, and averages and standard deviation values were calculated. 
A KD2-Pro handheld device (Decagon Devices Inc.) was employed to determine thermal conductivity. Thermal measurements were taken by a thick ( $6 \mathrm{~cm}$ long, $3.9 \mathrm{~mm}$ diameter) single RK-1 sensor based on the dual needle probe system (transient line source method) according to ASTM D5534-08 ${ }^{38}$ and Standard IEEE 442-198139. Before taking measurements, a standard (RH-1-01116, 0.387 $\pm 10 \% \mathrm{~W} / \mathrm{mK}$ ) was used to verify the sensor's good performance. Room temperature thermal conductivity was measured on four cubic specimens $\left(10 \times 10 \times 10 \mathrm{~cm}^{3}\right)$ of each formulation. A rotary hammer bit to drill pilot holes (6 cm long, $4 \mathrm{~mm}$ diameter) was necessary to accommodate the RK-1 sensor.

\section{Carbon footprint calculation}

The calculations and comparisons among the $\mathrm{CO}_{2}$ emissions related to the TCC, GCC and ECC systems were made.

To that end, the International Panel on Climate Change (IPCC) Guidelines for National Greenhouse Gas Inventories was followed ${ }^{40}$. The general methodology employed to estimate the $\mathrm{CO}_{2}$ emissions associated with a particular process involves the product of activity level data: the amount of the material processed or the amount of energy consumed, and an associated emission factor per unit of consumption/production according to:

$$
\mathrm{E}_{\mathrm{i}}=\mathrm{A}_{\mathrm{i}} \mathrm{EF} \mathrm{F}_{\mathrm{i}}
$$

Where $E_{i}=$ the process emission $(\mathrm{kg})$ of $\mathrm{CO}_{2}$ from each component or operation 'i'; $\mathrm{A}_{\mathrm{i}}=$ the amount of activity or processed material 'i'; and $\mathrm{EF}_{\mathrm{i}}=$ the emission factor associated with the $\mathrm{CO}_{2}$ per unit of activity or process material 'i’.

Two different phases were assessed: i) Phase 1: emissions associated with each single material which forms a cellular concrete (called emissions associated with the components, $E_{C}$ ); ii) Phase 2: emissions associated with the cellular concrete manufacture considering laboratory conditions (milling and mixing procedures) $\left(E_{M}\right)$. The carbon footprint calculation result was calculated as the sum of the emissions from its two phases (Equation (8)).

$$
\mathrm{E}_{\mathrm{TOTAL}, \mathrm{i}}=\mathrm{E}_{\mathrm{C}, \mathrm{i}}+\mathrm{E}_{\mathrm{M}, \mathrm{i}}
$$

Where "i" is the sample (CA, FR, FRR, SR or SRR).

Calculations were made to obtain, in the same context (laboratory conditions), $1 \mathrm{~m}^{3}$ of each material. For the volume of manufactured materials to be comparable, their same density was considered herein (600 $\mathrm{kg} / \mathrm{m}^{3}$ ). By considering this aspect, the currently commercial cellular concretes with the proposed alternatives and the same properties were compared.

The amounts of the solid precursor, combined water and solid alkali compounds present in each mix were obtained from the thermogravimetric analysis (TGA) with a Mettler-Toledo TGA 850. The obtained DTG curve provides the amount of water chemically combined in the samples in weight percentage. The weight difference corresponds to the solid phases: precursor, $\mathrm{Na}_{2} \mathrm{O}$ and $\mathrm{SiO}_{2}$. For a given dosage (w/b ratio, $\mathrm{Na}^{+}$molality and $\mathrm{SiO}_{2} / \mathrm{Na}_{2} \mathrm{O}$ molar ratio) the solid phases proportion in the samples is constant, and the amount of the precursor to obtain a cellular concrete with a given density can be determined by the following relationships showed in Figure 1. 


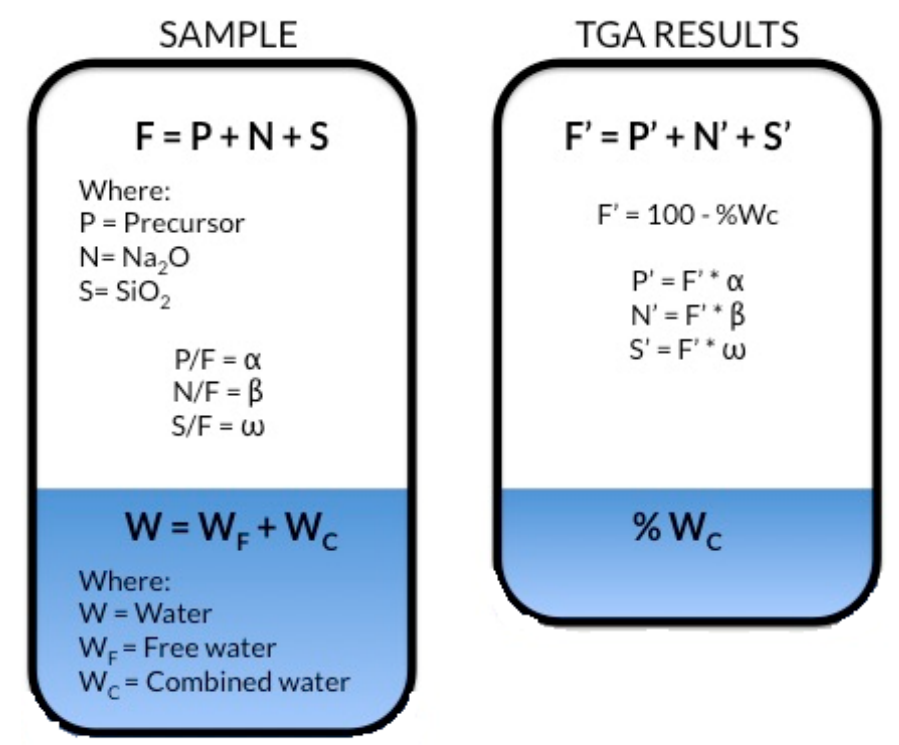

Fig 1. Methodology for obtaining the dosages of cellular concretes from TGA results.

\section{RESULTS AND DISCUSSION}

\subsection{Physical and mechanical characterisation}

Table 3 shows a summary of the results obtained in the experimental section of the cellular concretes studied in this work. 
Table 3: TCC, GCC and ECC properties obtained from tests

\begin{tabular}{|c|c|c|c|c|}
\hline & \multirow{2}{*}{ Natural density $\left(\mathrm{kg} / \mathrm{m}^{3}\right)$} & \multicolumn{2}{|c|}{ Compressive strength (MPa) } & \multirow{2}{*}{$\begin{array}{l}\text { Thermal Conductivity } \\
\qquad(\mathrm{W} / \mathrm{mK})\end{array}$} \\
\hline & & $7 d$ & $28 \mathrm{~d}$ & \\
\hline CA & $618 \pm 2$ & $4.5 \pm 0.4$ & $6.5 \pm 0.4$ & $0.182 \pm 0.001$ \\
\hline FR & $813 \pm 2$ & $3.5 \pm 0.2$ & $4.3 \pm 0.4$ & $0.083 \pm 0.003$ \\
\hline FRR & $782 \pm 4$ & $2.6 \pm 0.4$ & $3.2 \pm 0.3$ & $0.113 \pm 0.005$ \\
\hline SR & $474 \pm 4$ & $1.6 \pm 0.5$ & $2.6 \pm 0.2$ & $0.281 \pm 0.007$ \\
\hline SRR & $611 \pm 4$ & $3.2 \pm 0.2$ & $4.6 \pm 0.3$ & $0.224 \pm 0.007$ \\
\hline
\end{tabular}

The TCC based on OPC and commercial aluminium powder (A), CA sample, had a natural density of $618 \pm 2 \mathrm{~kg} / \mathrm{m}^{3}$ and its compressive strength yielded 4.5 and $6.5 \mathrm{MPa}$ for 7 and 28 curing days, respectively. These values are in line with those reported in the literature, where values of $600 \mathrm{~kg} / \mathrm{m}^{3}$ are related with compressive strengths of 2.8 to $6.3 \mathrm{MPa}$ at 28 days ${ }^{5,41}$.

For the GCC system, activated by a traditional alkali solution ( $\mathrm{NaOH}$, commercial waterglass and water), replacing the commercial aluminium powder (A) by recycled aluminium foil (RAF) allowed interesting cellular systems to be obtained.

With the addition of RAF, the FR resultant material yielded a natural density of $813 \pm 2 \mathrm{~kg} / \mathrm{m}^{3}(31.6 \%$ higher than the TCC system). Compressive strength varied from 3.5 after 7 days to $4.3 \mathrm{MPa}$ after 28 days. In contrast with its natural density value, this mechanical behaviour represents a $34.1 \%$ reduction compared to the TCC system. These results do not agree with those reported by Font et al..$^{18}$ in their previous research work where the geopolymer samples with FCC allowed the natural density to lower and yielded a compressive strength gain compared to the TCC systems. It could be attributed to the difference in the w/b ratio and to specimen dimensions. Since cellular concretes should flow to avoid compaction or vibration, for a larger volume material the required w/b ratio would have to be equal 0.6. This value involves higher fluid consistence and, consequently, extends the time spent on gaining matrix stability, which allows gas entrapping. During this time, most of the generated gas from the aluminium reaction was not entrapped, and the resultant void-system in the paste produced a poorer performing system in terms of natural density and strength. In a previous research, for foamed concrete, Nambiar et al. ${ }^{42}$ and Zhang et al. ${ }^{6}$ established that a controlled $\mathrm{w} / \mathrm{b}$ range is required to develop an optimal and stable void system in the matrix.

With the use of BFS precursor, the RAF reaction into the cementitious matrix involves an effective cellular structure and the resultant average density of the SR samples was $474 \pm 4 \mathrm{~kg} / \mathrm{m}^{3}(23.3 \%$ lower than CA). The mechanical strength was 1.6 MPa after 7 curing days, and 2.6 MPa after 28 days. The strength value was $60.9 \%$ lower than the CA compressive strength. This expected behaviour in the SR samples agrees with the linear relationship between density and compressive strength in cellular concrete systems. In this case, given the low w/b ratio of 0.35 , most of hydrogen gas was entrapped in the matrix, which led to lower natural density compared to TCC.

The ECC systems, where the traditional activating solution ( $\mathrm{NaOH}$, commercial waterglass and water) was replaced by a mixture of $\mathrm{NaOH}$ and RHA in water, showed interesting behaviour. Concrete prepared with FCC (FRR) had natural density of $782 \pm 4 \mathrm{~kg} / \mathrm{m}^{3}$, which was $26.6 \%$ higher than CA, and was similar to the FR sample. Compressive strength yielded from 2.6 MPa after 7 curing days to $3.2 \mathrm{MPa}$ after 28 curing days. This mechanical behaviour was $51.3 \%$ lower than that obtained in the CA samples which, as with the FR samples, contrasts with the strength-density linear relationship usually found in cellular concretes. This can be explained by the same discussion as that mentioned above based on the w/b ratio. In the BFS-based ECC system (SRR samples), the results showed an interesting evolution when WG 
was replaced by RHA and its natural density was similar to that obtained in the CA samples $(611 \pm 4$ $\mathrm{kg} / \mathrm{m}^{3}$ ). Compressive strength yielded 3.2 MPa after 7 days of curing and 4.6 MPa after 28 days, values significantly higher than those obtained for SR concrete.

These results highlighted that the amount of silica soluble from RHA allows obtain an appropriate alkali activator reagent, which potentially reacts with the precursors forming the cementing gels. In any case, the use of an aerating agent as well as replacing the commercial aluminium powder with recycled aluminium foil (RAF) allowed good-performance cellular concretes to be prepared.

Regarding thermal properties (Table 3), the traditional cellular samples (CA) yield $0.182 \mathrm{~W} / \mathrm{mK}$. With the alternative geopolymer systems, the highest value was obtained for SR sample $(0.281 \mathrm{~W} / \mathrm{mK})$ followed by SRR $(0.224 \mathrm{~W} / \mathrm{mK})$, FRR $(0.113 \mathrm{~W} / \mathrm{mK})$ and finally FR, which yield the lowest value $(0.083$ $\mathrm{W} / \mathrm{mK}$ ). With the results obtained herein, we highlight the good insulation performance of the studied alternative cellular materials. Specifically, regards to FCC based cellular concretes, the lowest thermal conductivity was obtained despite they had the highest natural density. This behaviour suggested that the pore distribution of aerated system was very advantageous when FCC is used as precursor.

A clear visual comparative of the physical properties is shown in Figure 2. The following coefficients (Equations (9) (10) and (11)) were determined by analysing the results of the physical tests (density, compressive strength and thermal conductivity), and after considering the ratio between each alternative cellular concrete based on waste precursors and recycled aluminium foil (GCC and ECC) respect the TCC system based on OPC and commercial aluminium powder. These coefficients allowed us to compare the potential of the GCC and ECC systems in terms of the selected properties.

$$
\vartheta_{d}=\frac{\rho_{x}}{\rho_{R}}
$$

Where:

$\vartheta_{d}=$ Density ratio coefficient

$\rho_{\mathrm{x}}=$ Density for the alternative cellular concrete (FR, FRR, SR or SRR)

$\rho_{\mathrm{R}}=$ Density for the TCC (CA)

$$
\vartheta_{s}=\frac{r_{x}}{r_{R}}
$$

Where:

$\vartheta_{\mathrm{s}}=$ Compressive strength ratio coefficient at 28 curing days

$r_{x}=$ Compressive strength for the alternative cellular concrete at 28 days (FR, FRR, SR or SRR)

$r_{R}=$ Compressive strength for the TCC (CA) at 28 curing days 


$$
\vartheta_{t}=\frac{k_{x}}{k_{R}}
$$

Where:

$\vartheta_{\mathrm{t}}=$ Thermal conductivity ratio coefficient

$\mathrm{k}_{\mathrm{x}}=$ Thermal conductivity for the alternative cellular concrete (FR, FRR, SR or SRR)

$\mathrm{k}_{\mathrm{R}}=$ Thermal conductivity for the TCC (CA)

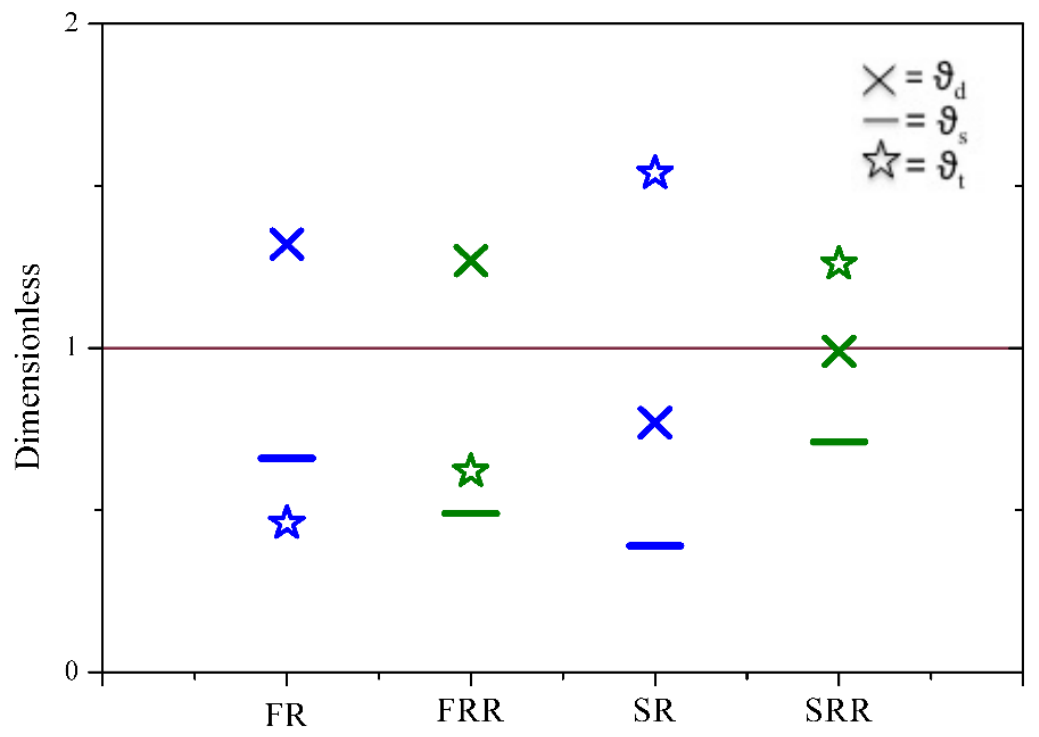

Fig 2. Density, compressive strength and thermal conductivity ratio coefficients for the GCC and ECC systems.

The horizontal solid line shown in Figure 2 represents the unit value of the ratio coefficients. The values of $\vartheta_{\mathrm{d}}, \vartheta_{\mathrm{s}}$ and $\vartheta_{\mathrm{t}}$ above the line denote that the corresponding property of the material is higher than that for the CA reference, and the values below the line mean that it is lower than the CA reference one.

Since, a good performance of cellular concrete involve its low density, moderate compressive strength and low thermal conductivity, from Figure 2 it is possible to denote that:

- $\quad$ FCC samples are denser than the reference material, being the FRR density ratio slightly closer to the unit. Respect to the use of BFS as the precursor, the SR density is below the line (corresponding to the lower value), while the SRR density coefficient is the closer one of the solid line. As for FCC samples as for BFS the density coefficients are closer to the unit when RHA is used to replace the silica from WG.

- Analysing the compressive strength ratio coefficients it is clearly highlighted the directly relation with the density for FCC samples and the inverse relationship for BFS samples. The strength values for all alternative cellular concretes evaluated were lower than that obtained for CA. 
- The lowest thermal conductivity values were yielded for system in which FCC is used as the precursor despite their density values.

- By considering the three physical properties coefficients, the use of RHA involves the corresponding ratio coefficients closer than the unit (solid line).

\subsection{Carbon footprint calculation}

The components and manufacturing process for each cellular concrete, considered with the $\mathrm{CO}_{2}$ emissions calculations, are summarised in Table 4.

Table 4: Overview of each cellular concrete system component (C) and manufacturing process (M) for carbon footprint calculation.

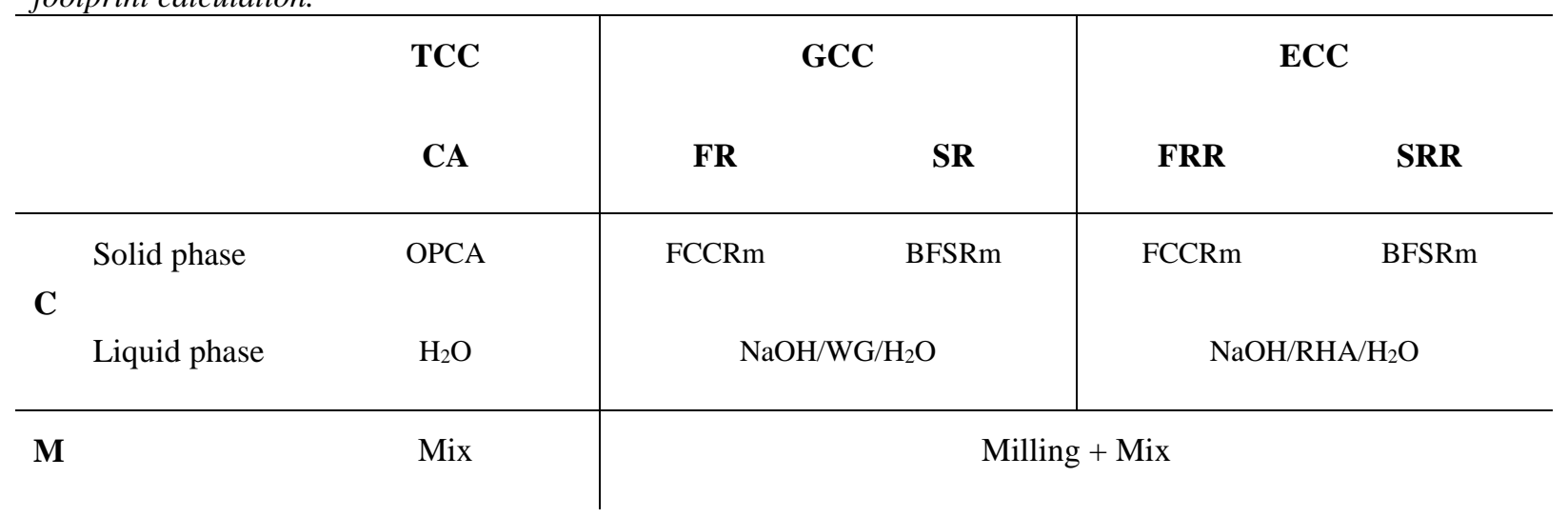

Two phases for three different cellular systems were assessed, which were as follows.

Phase 1: Emissions associated with components ( $\left.E_{C}\right)$

Table 5 shows the resultant dosage of the CA, FR, SR, FRR and SRR cellular concretes by considering that these must have a density of $600 \mathrm{~kg} / \mathrm{m}^{3}$ (dry conditions).

If we consider a CA sample with a density of $600 \mathrm{~kg} / \mathrm{m}^{3}$, it represents $600 \mathrm{~kg}$ of total weight, formed by OPC and combined $\mathrm{H}_{2} \mathrm{O}$. This water is chemically combined to form the typical CSH, ettrringite, CASH, $\mathrm{CAH}$ and $\mathrm{CH}$ products, among others, from hydration reactions (C-CaO; $\mathrm{S}-\mathrm{SiO}_{2} ; \mathrm{A}-\mathrm{Al}_{2} \mathrm{O}_{3} ; \mathrm{H}-\mathrm{H}_{2} \mathrm{O}$ ). The total mass loss observed on the DTG curve $\left(35-600^{\circ} \mathrm{C}\right.$ temperature range) of the CA paste (20.32\%) (Figure 3) represents this chemically combined water. This means that $79.68 \%$ of the sample corresponds to OPCA.

The emission factor associated with clinker production was $1 \mathrm{~kg}$ of $\mathrm{CO}_{2}$ per $\mathrm{kg}$ of cement ${ }^{3,15,43}$. If we consider that the used OPC was 95\% composed of clinker, the emission factor adopted for the calculation would be $0.95 \mathrm{CO}_{2} / \mathrm{kg}$. Zero emission was considered for water supply. Regarding the emission associated with the aerating agent, the corresponding factor for gas generator production was $11.5 \mathrm{~kg}$ $\mathrm{CO}_{2}$ per $\mathrm{kg}$ of $\mathrm{A}$. In this case, the emission factor related to aluminium powder metallurgy processing (air or gas atomisation) was not considered because this value was not available from the consulted databases. Finally by using Equation (7), the total $\mathrm{CO}_{2}$ emissions associated with components per $\mathrm{m}^{3}$ of TCC were calculated $\left(\mathrm{E}_{\mathrm{C}, \mathrm{CA}}\right)$, resulting $467.0 \mathrm{~kg} \mathrm{CO} / \mathrm{m}^{3} \mathrm{CA}$.

For the GCC samples, an FR sample with a density of $600 \mathrm{~kg} / \mathrm{m}^{3}$ represented $600 \mathrm{~kg}$ of the resultant weight, formed by FCC, $\mathrm{Na}_{2} \mathrm{O}, \mathrm{SiO}_{2}$ and chemically combined water (to form NASH gel). By the total mass loss from the DTG curve (14.09\%) (Figure 3), the chemically combined water was determined. From the alkaline solution stoichiometry $\left(\mathrm{Na}^{+}\right.$molality=7.5 and $\mathrm{SiO}_{2} / \mathrm{Na}_{2} \mathrm{O}$ molar ratio $\left.=1.7\right)$ and the w/b ratio (0.6), the $\mathrm{Na}_{2} \mathrm{O}$ and $\mathrm{SiO}_{2}$ percentages were constant compared to the solid precursor. The same ratios were considered with the SR sample, which yielded a total mass loss of $14.19 \%$ on the DTG curve and had the same stoichiometry for the activating solution, with a w/b ratio equal to 0.35 .

Since FCC and BFS are industrial wastes and RAF was from recycled supply, no emission associated with them was considered. The manufacture of $\mathrm{NaOH}$ and commercial waterglass was taken into account (no emission associated with water supply). Both emission factors, which corresponded to $\mathrm{NaOH}$ and 
WG, were obtained from the SimaPro7.1 program databases (demo version, Pré Consultants Company of The Netherlands, LCA software specialist). The emission factors were $1.12 \mathrm{~kg} \mathrm{CO}_{2}$ of $\mathrm{NaOH}$ and 1.2 $\mathrm{kg} \mathrm{CO} 2$ per $\mathrm{kg}$ of the commercial waterglass solution. Finally by using Equation (7), the total $\mathrm{CO}_{2}$ emissions associated with components per $\mathrm{m}^{3}$ of each GCC were calculated, which were $\mathrm{E}_{\mathrm{C}, \mathrm{FR}}=322.5$ $\mathrm{kg} \mathrm{CO} 2 / \mathrm{m}^{3}$ for $\mathrm{FR}$ and $\mathrm{E}_{\mathrm{C}, \mathrm{SR}}=207.7 \mathrm{~kg} \mathrm{CO}_{2} / \mathrm{m}^{3}$ for SR.

In the ECC systems, WG was replaced with RHA. The solid components of the FRR and SRR samples were the same as for FR and SR, respectively, and the alkali solution based on $\mathrm{H}_{2} \mathrm{O}, \mathrm{NaOH}$ and RHA composed the liquid phase (Table 4). The amount of each component required in the $600 \mathrm{~kg} / \mathrm{m}^{3} \mathrm{FRR}$ or SRR dosages was obtained by the same means as for FR and SR, explained above from the thermogravimetric data and stoichiometry of the activating mixture (see Table 5 and Figure 3).

According to the above $E_{C, F R}$ and $E_{C, S R}$ calculations, no emissions associated with FCC, BFS and RAF were considered. Moreover, RHA is an agricultural waste, thus no emissions associated with it were considered. In this case, only the $\mathrm{CO}_{2}$ emissions from $\mathrm{NaOH}$ manufacturing were contemplated. Thus the $\mathrm{E}_{\mathrm{C}, \mathrm{FRR}}$ and $\mathrm{E}_{\mathrm{C}, \mathrm{SRR}}$ values were 88.3 and $65.8 \mathrm{~kg} \mathrm{CO}_{2} / \mathrm{m}^{3}$, respectively.

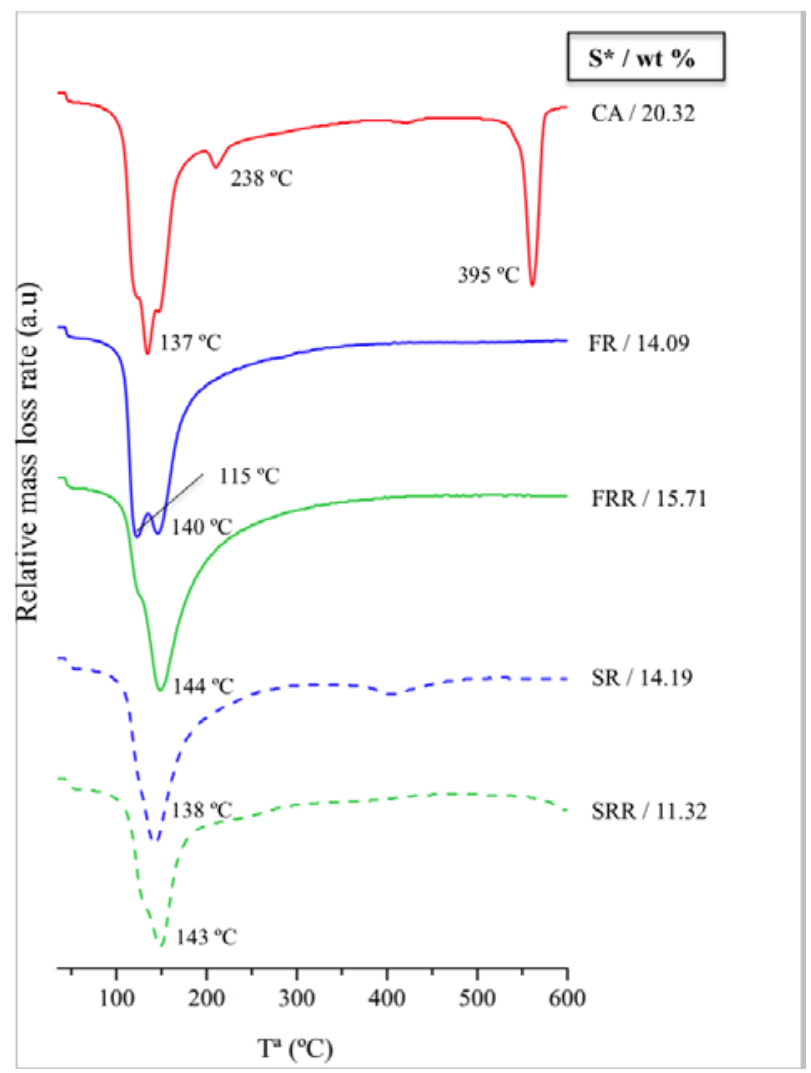

Fig 3. The DTG curves of the CA, FR, FRR, SR and SRR samples.

S*/wt \% = sample/total mass loss \% per weight 
Table 5: Dosages of CA, FR, SR, FRR and SRR samples to obtain a cellular concrete with a density of $600 \mathrm{~kg} / \mathrm{m}^{3}$.

\begin{tabular}{|c|c|c|c|c|c|c|c|c|c|}
\hline \multicolumn{2}{|c|}{ CA } & \multicolumn{2}{|c|}{ FR } & \multicolumn{2}{|c|}{ SR } & \multicolumn{2}{|c|}{ FRR } & \multicolumn{2}{|c|}{ SRR } \\
\hline & & FCC & $397.4 \mathrm{~kg}$ & BFS & $438.8 \mathrm{~kg}$ & FCC & $375.6 \mathrm{~kg}$ & BFS & $435.2 \mathrm{~kg}$ \\
\hline OPC & $480.0 \mathrm{~kg}$ & RAF & $0.8 \mathrm{~kg}$ & RAF & $0.9 \mathrm{~kg}$ & RAF & $0.8 \mathrm{~kg}$ & RAF & $0.9 \mathrm{~kg}$ \\
\hline A & $0.9 \mathrm{~kg}$ & $\mathrm{H}_{2} \mathrm{O}$ & $95.4 \mathrm{~kg}$ & $\mathrm{H}_{2} \mathrm{O}$ & $61.4 \mathrm{~kg}$ & $\mathrm{H}_{2} \mathrm{O}$ & $363.9 \mathrm{~kg}$ & $\mathrm{H}_{2} \mathrm{O}$ & $195.8 \mathrm{~kg}$ \\
\hline $\mathrm{H}_{2} \mathrm{O}$ & $240.0 \mathrm{~kg}$ & $\mathrm{NaOH}$ & $48.5 \mathrm{~kg}$ & $\mathrm{NaOH}$ & $31.2 \mathrm{~kg}$ & $\mathrm{NaOH}$ & $78.9 \mathrm{~kg}$ & $\mathrm{NaOH}$ & $58.7 \mathrm{~kg}$ \\
\hline & & WG & $223.5 \mathrm{~kg}$ & WG & $144.0 \mathrm{~kg}$ & RHA & $76.7 \mathrm{~kg}$ & RHA & $57.1 \mathrm{~kg}$ \\
\hline
\end{tabular}

Figure 4 shows the percentage of contribution to $\mathrm{CO}_{2}$ emissions from the components and the percentage that represents each component in the final dosage material.

It is noticeable in the CA samples, that the CO2 emissions coming from the OPC (whose are $66.6 \%$ of the total dosage) represent nearly $97 \%$ of the total component emissions, and the remaining $3 \%$ is caused by the use of powdered aluminium (which represents merely $0.16 \%$ of the dosage).

The application of both proposed GCC systems yielded a marked $E_{C}$ reduction compared to the TCC system emissions. $E_{C, F R}$ and $E_{C, S R}$ gave $30.9 \%$ and 55.5\% less than $E_{C, C A}$, respectively. We highlight that in these two GCC systems, the emissions from the WG manufacturing, represented nearly 83\% despite this component is in $29.2 \%$ and $21.3 \%$ in the FR and SR dosages, respectively. The remaining $17 \%$ of $\mathrm{E}_{\mathrm{C}}$, was related to $\mathrm{NaOH}$ manufacturing (Figure 4).

Finally regarding ECC (where the total component emissions were associated with $\mathrm{NaOH}$ ), for the FRR samples the $\mathrm{NaOH}$ dosage represented $9.9 \%$ of the total weight and the resultant $\mathrm{E}_{\text {C,FRR }}$ was $88.3 \mathrm{~kg}$ $\mathrm{CO}_{2} / \mathrm{m}^{3} \mathrm{FRR}$. This $\mathrm{E}_{\mathrm{C}, \mathrm{FRR}}$ was $72.6 \%$ lower than $\mathrm{E}_{\mathrm{C} \text {,FR }}$ and $81.1 \%$ lower than $\mathrm{E}_{\mathrm{C}, \mathrm{CA}}$. For the SRR samples, the $\mathrm{NaOH}$ dosage represented $7.8 \%$ of the total weight and the resultant $\mathrm{E}_{\mathrm{C}, \mathrm{SRR}}$ was $65.8 \mathrm{~kg} \mathrm{CO}_{2} / \mathrm{m}^{3}$ SRR. This $E_{C, S R R}$ was $68.3 \%$ lower than $E_{C, S R}$ and $85.9 \%$ lower than $E_{C, C A}$. 


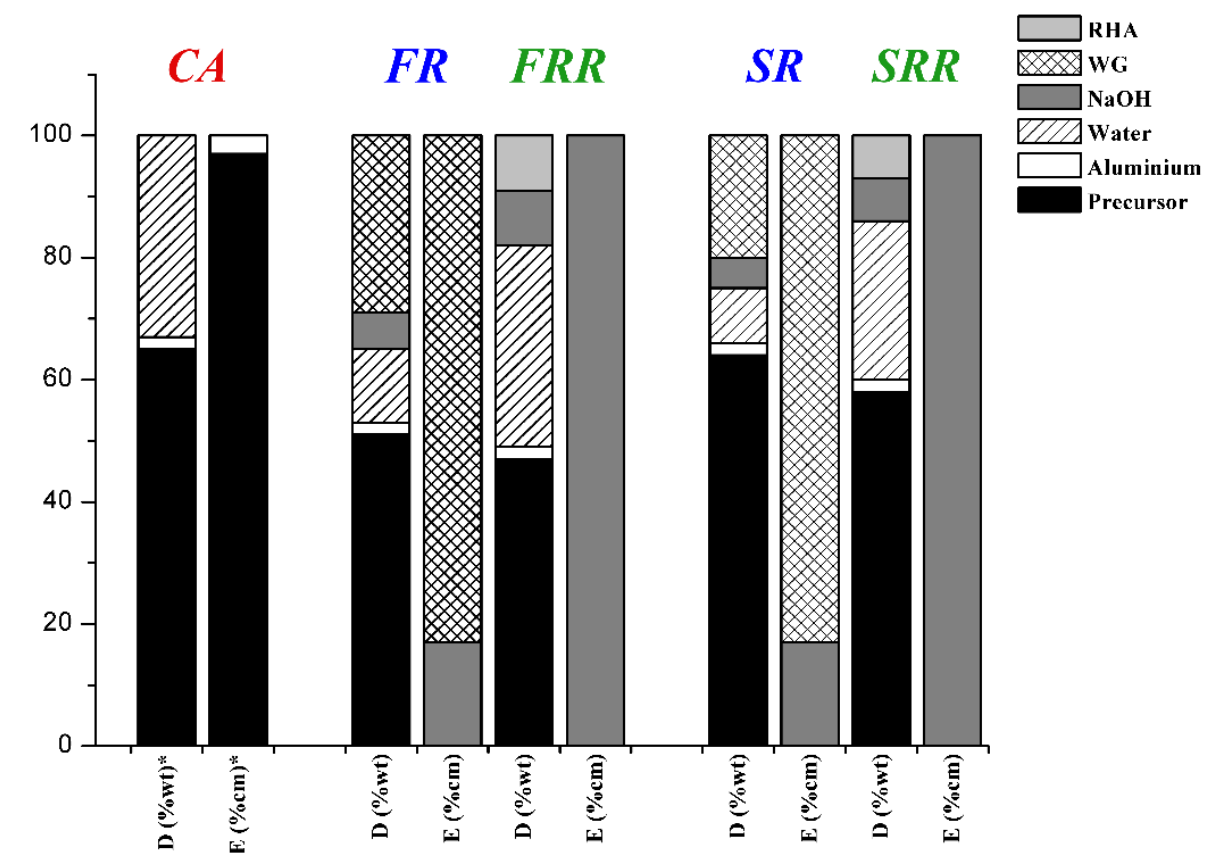

Fig 4. Comparison of the contribution percentage to the $\mathrm{CO}_{2}$ emissions from components (* $E$ (\%cm):) and the percentage that represents each component in the final dosage material ( $D$ (\% wt): weight percentage) for the CA, FR, FRR, SR and SRR cellular concretes.

It can be focus this noticeable reduction in $\mathrm{CO}_{2}$ emissions in relation to the cellular concrete components mainly on the replacement of chemically synthetic reagent WG. The synthesis of commercial waterglass consists in the reaction of quartz and sodium carbonate, which is carried out at high temperature (above $1300^{\circ} \mathrm{C}$ ) and involves $\mathrm{CO}_{2}$ emissions from sodium carbonate decomposition (Equation (5)) and the energy required to heat the quartz/Na $\mathrm{Na}_{2} \mathrm{CO}_{3}$ mixture in a furnace. These results agree with the statements found in several works which have centred on searching for an alternative silica source in alkali-activated materials $21,43,44$.

It is worth considering that the aluminium contributions in emissions were much lower: 3\% for TCC production, and were completely null for the alternative GCC and ECC systems. However, we must take into account that no aluminium powder metallurgy processing was considered for TCC production. In any case, the way proposed to include RAF in the FCC/BFS milling process became a new ecological material to remove the emissions associated with this commercial gas-generating reagent.

\section{Phase 2: Emissions associated with the manufacture process $\left(E_{M}\right)$}

The manufacturing of TCC, GCC and ECC involves assessing three different activities: i) the pretreatment of raw materials; ii) the mixing procedure; iii) the curing procedure. The evaluated cellular concrete samples were cured at room temperature and, for this reason, only the first two activities were considered herein. Additionally with ECC systems, no emissions associated with dissolution preparations in a thermal bottle were produced. Since no industrial process exists for GCC and ECC production, calculations were made by considering the same manufacture conditions as those used to produce concrete in a laboratory.

The raw materials used to prepare TCC (OPC and A) have an industrial manufacture system and their pre-treatment was not necessary. For the GCC and ECC systems, as in Section 2.2 "Materials" was explained, FCCRm and BFSRm solid mixes were achieved by the grinding treatment. To obtain FCCRm, FCC and RAF were co-milled in a ball mill at $0.3 \mathrm{~kW}$ electric powers, and capacity was $300 \mathrm{~g}$ and 
grinding time was 20 minutes. The same ball mill was used to obtain BFSRm but, in this case, capacity was $450 \mathrm{~g}$ for 30 minutes.

The mixing procedure was the same for the TCC, GCC and ECC systems, and only mixing time differed. As explained in Section 2.2 "Experimental procedure", an AEG SBE705RE power drill connected to a paint mixer was used for samples preparation. This power drill works at $0.705 \mathrm{~kW}$ and the capacity for each mix cycle was $0.012 \mathrm{~m}^{3}$. For the CA samples the mixing time lasted 150 seconds ( 2.5 minutes), but it was 120 seconds (2 minutes) for the GCC and ECC systems.

For these calculations, and as with the mill and mix procedures, we took the national average value provided by IDAE as the emission factor of energy use, which is $0.25 \mathrm{~kg} \mathrm{CO}_{2}$ per $\mathrm{kWh}^{45}$.

With these considerations, the calculations of the emissions associated with the manufacture that corresponded to each sample were made by Equation (7) and the results were: $E_{M, C A}=0.6 \mathrm{~kg} \mathrm{CO} 2 / \mathrm{m}^{3}$ $\mathrm{CA}, E_{M, F R}=34 \mathrm{~kg} \mathrm{CO} / \mathrm{m}^{3} \mathrm{FR}, E_{M, S R}=37.5 \mathrm{~kg} \mathrm{CO} / \mathrm{m}^{3} \mathrm{SR}, E_{M, F R R}=32.1 \mathrm{~kg} \mathrm{CO}_{2} / \mathrm{m}^{3} \mathrm{FRR}$ and $E_{M, S R R}=$ $37.1 \mathrm{~kg} \mathrm{CO} / \mathrm{m}^{3} \mathrm{SRR}$.

Figure 5 shows a comparison of the $\mathrm{CO}_{2}$ emissions from the different materials and operations for each concrete. Calculated $\mathrm{kg}$ of $\mathrm{CO}_{2}$ per $\mathrm{m}^{3}$ of material, the relative values are plotted and absolute values are provided.

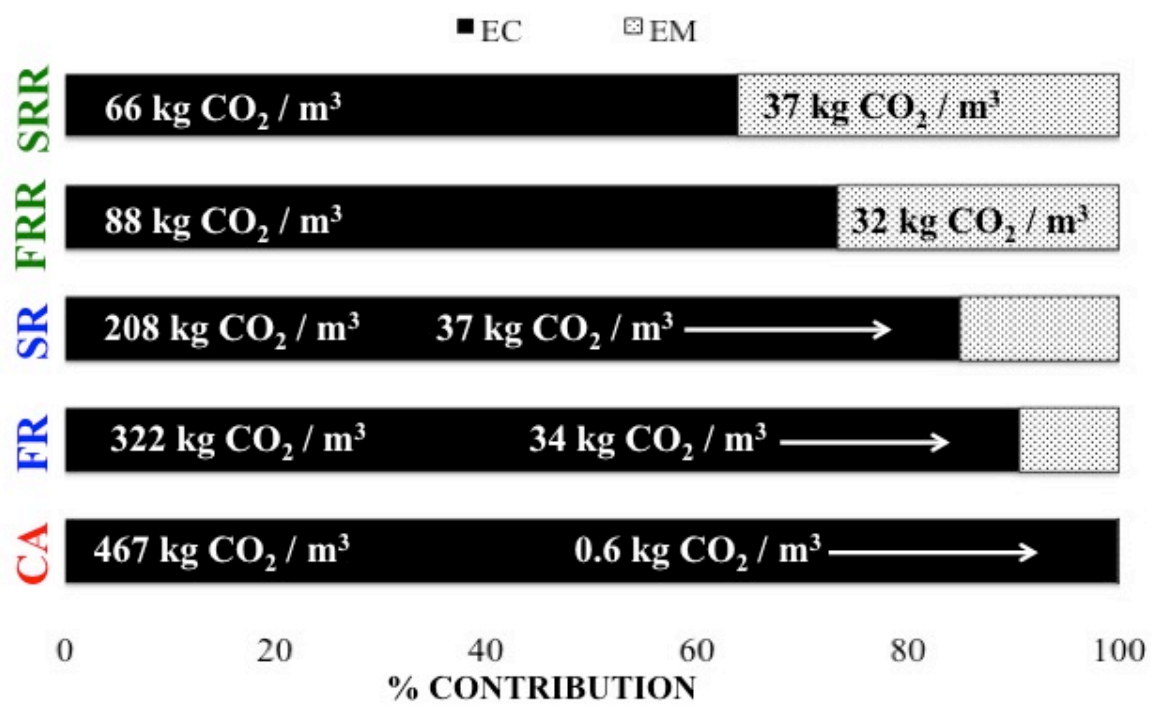

Fig 5. Comparison of the relative $\mathrm{CO}_{2}$ emissions contributions from the components ( $\left.E_{\mathrm{C}}\right)$ and manufacture processes $\left(E_{M}\right)$ for the CA, FR, SR, FRR and SRR cellular concretes. The absolute $\mathrm{CO}_{2}$ emissions values are given in each bar.

As we can see, no influence of the TCC manufacture process was perceived, and total emission was related mainly to its components. However, as in both the GCC and ECC systems, manufacturing influenced the total $\mathrm{CO}_{2}$ emissions. Indeed the effect of the milling procedure was more important than the mixing procedure for all the samples. An analysis of the results revealed that: $\mathrm{E}_{\mathrm{M}}$, FR represents $9.5 \%$,

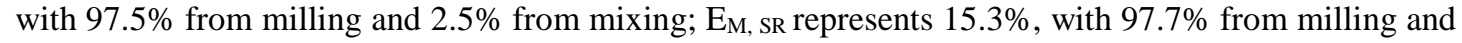
2.3\% form mixing; $E_{M}$, FRR represents $26.7 \%$, with $97.3 \%$ from milling and $2.7 \%$ form mixing; $E_{M}$, SRR represents $31.1 \%$, with $97.7 \%$ from milling and $2.3 \%$ form mixing. The absolute $\mathrm{CO}_{2}$ emissions produced from manufacturing were higher when the required solid material increased (Table 5) due to the high-energy requirement of pre-treatment.

These results can be explained because, nowadays for TCC, an industrial process of OPC and A manufacturing exists, and no pre-treatment in laboratory is required. If the same conditions for GCC and ECC systems could be considered, the emissions of this materials would be lower. 
Finally, the resultant carbon footprint of each material was calculated by Equation (8). Figure 6 shows a comparison of the total $\mathrm{CO}_{2}$ emissions from the CA, FR, SR, FRR and SRR cellular concretes analysed in the present study.

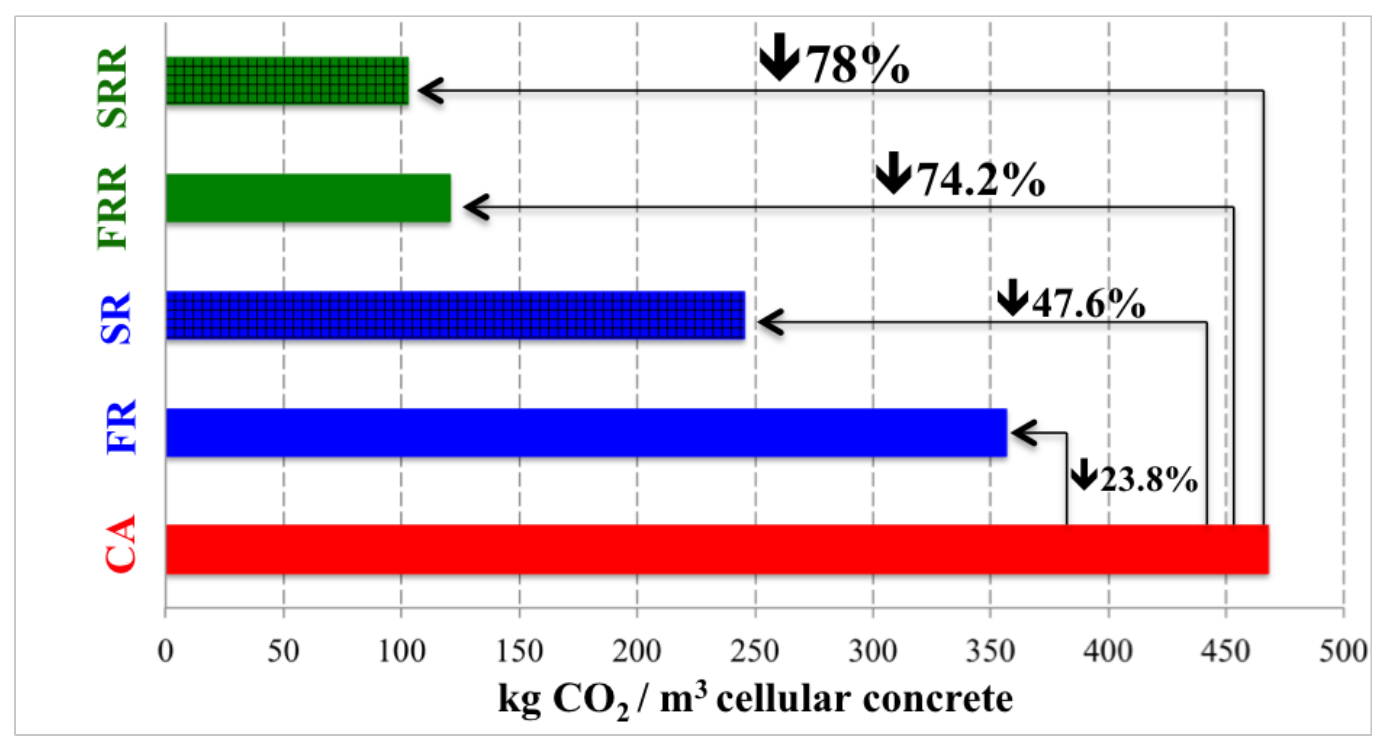

Fig 6. The total $\mathrm{CO}_{2}$ emissions associated with cellular concretes $C A, F R, S R, F R R$ and SRR and reductions in $\mathrm{CO}_{2}$ emissions compared to the CA sample (the TCC system).

For TCC, total emissions were $467.6 \mathrm{~kg} \mathrm{CO} / \mathrm{m}^{3} \mathrm{CA}$. For GCC, where OPC and A were replaced with alternative raw materials (FCCRm and BFSRm, respectively), the total $\mathrm{CO}_{2}$ emissions significantly reduced: i) the total emissions for the FR sample were $356.5 \mathrm{~kg} \mathrm{CO}_{2} / \mathrm{m}^{3} \mathrm{FR}$, which is $23.8 \%$ lower than those for the CA sample; ii) for the SR sample, they were $245.2 \mathrm{~kg} \mathrm{CO} / \mathrm{m}^{3} \mathrm{SR}, 47.6 \%$ lower than those for CA. The last development step, where commercial waterglass was replaced by RHA (ECC systems), gave a relevant reduction in the total carbon footprint: $66.2 \%$ vs. FR and $74.2 \%$ vs. CA for the FRR system ( $\left.120.4 \mathrm{~kg} \mathrm{CO}_{2} / \mathrm{m}^{3} \mathrm{FRR}\right)$, and $58 \%$ vs. SR and $78 \%$ vs. CA for the SRR systems $\left(102.9 \mathrm{~kg} \mathrm{CO}_{2} / \mathrm{m}^{3}\right.$ SRR).

\section{CONCLUSIONS}

In this research, the density of the proposed alternative cellular concrete (FR, FRR, SR and SRR) was lower than $1000 \mathrm{~kg} / \mathrm{m}^{3}$, which represents suitable lightweight insulation behaviour. Besides, mechanical behaviour came close to TCC in all the evaluated alternative cellular concretes.

The obtained results for the new proposed ECC demonstrated the high effectiveness of soluble silica from RHA to replace the silica from WG. Replacing the traditional alkaline solution by a mixture of RHA and $\mathrm{NaOH}$ allowed new cellular concrete to be prepared with similar properties to those found for the equivalent systems with WG. This implies an interesting chance to reduce the use of synthetic chemical reagents for preparing this cellular concrete type.

The results of the carbon footprint calculations revealed that with the new ECC it is possible to minimise $\mathrm{CO}_{2}$ emissions by more than $70 \%$ versus TCC emissions. The factors that most contributed to the carbon footprint were: i) the OPC in TCC; ii) WG as well as milling in the GCC systems; iii) only milling in the ECC systems. Calculations were made by considering laboratory conditions: if the industrial milling of the alternative raw materials required for the GCC and ECC systems manufacturing could be considered, the emissions from milling would be much lower. For the GCC systems, the contribution of commercial waterglass (WG) was more than $80 \%$. Indeed the new alternative ECC allowed the possibility of reducing greenhouse gas emissions and contributing to sustainable development by integrating green chemistry principles into construction materials by reusing wastes, including those related to aluminium-based gas generators. 


\section{Acknowledgements}

The authors acknowledge the financial support from the Universitat Politècnica de València (UPV) through internal project GEOCELPLUS. The authors like also to express special grateful to Dra. Mrs. Josefa L. Roselló Caselles for recycled aluminium foil, and to the Electronic Microscopy Service of the UPV. Thanks are given to DACSA, Cementval and BPOil for supplying samples.

\section{Bibliography}

1 O. Ortiz, F. Castells and G. Sonnemann, Constr. Build. Mater., 2009, 23, 28-39.

2 L. F. Cabeza, L. Rincón, V. Vilariño, G. Pérez and A. Castell, Renew. Sustain. Energy Rev., 2014, 29, 394-416.

3 M. Jiang, X. Chen, F. Rajabipour and C. T. Hendrickson, J. Infrastruct. Syst., 2014, 20, 1-9.

$4 \quad$ K. Cavanaugh and J. F. Speck, Concrete, 2002, 1-21.

5 N. Narayanan and K. Ramamurthy, Cem. Concr. Compos., 2000, 22, 321-329.

6 Z. Zhang, J. L. Provis, A. Reid and H. Wang, Constr. Build. Mater., 2014, 56, $113-127$.

7 H. Esmaily and H. Nuranian, Constr. Build. Mater., 2012, 26, 200-206.

8 R. Arellano Aguilar, O. Burciaga Díaz and J. I. Escalante García, Constr. Build. Mater., 2010, 24, 1166-1175.

9 T. W. Bremner, P. M. Carkner, M. Healy and A. Litvin, Man. Concr. Pract., 1997, 2-6.

10 D. K. Panesar, Constr. Build. Mater., 2013, 44, 575-584.

11 B. Dolton and C. Hannah, 2006, 1-11.

12 K. L. Scrivener and R. J. Kirkpatrick, Cem. Concr. Res., 2008, 38, 128-136.

13 E. Gartner, Cem. Concr. Res., 2004, 34, 1489-1498.

14 A. Palomo and J. I. López de la Fuente, Cem. Concr. Res., 2003, 33, 281-288.

15 P. Duxson, J. L. Provis, G. C. Lukey and J. S. J. van Deventer, Cem. Concr. Res., 2007, 37, 1590-1597.

16 P. J. Davidovits, Geopolymer 2002 Conf., 2002, 1-16.

17 J. Davidovits, First Int. Conf. Alkaline Cem. Concr., 1994, 131-149.

18 A. Font, M. V. Borrachero, L. Soriano, J. Monzó and J. Payá, J. Clean. Prod., 2017, 168, 1120-1131. 
19 J. L. Provis, Cem. Concr. Res., , DOI:10.1016/j.cemconres.2017.02.009.

20 A. Mellado, C. Catalán, N. Bouzón, M. V. Borrachero, J. M. Monzó and J. Payá, RSC Adv., 2014, 4, 23846-23852.

21 L. K. Turner and F. G. Collins, Constr. Build. Mater., 2013, 43, 125-130.

22 J. R. Dodson, E. C. Cooper, A. J. Hunt, A. Matharu, J. Cole, A. Minihan, J. H. Clark and D. J. Macquarrie, Green Chem., 2013, 15, 1203.

23 N. Bouzón, J. Payá, M. V. Borrachero, L. Soriano, M. M. Tashima and J. Monzó, Mater. Lett., 2014, 115, 72-74.

24 J. C. B. Moraes, A. Font, L. Soriano, J. L. Akasaki, M. M. Tashima, J. Monzó, M. V. Borrachero and J. Payá, Constr. Build. Mater., , DOI:10.1016/j.conbuildmat.2018.03.230.

25 M. Torres-Carrasco and F. Puertas, J. Clean. Prod., 2015, 90, 397-408.

26 EST:

http://www.fao.org/economic/est/publications/publicaciones-sobre-el\#.WrfjcGYrw_U, (accessed 25 March 2018).

27 J. C. Marchal, D. J. Krug III, P. McDonnell, K. Sun and R. M. Laine, Green Chem., 2015, 17, 3931-3940.

28 T. Luukkonen, Z. Abdollahnejad, J. Yliniemi, P. Kinnunen and M. Illikainen, J. Clean. Prod., 2018, 187, 171-179.

29 R. U. Ayres, 1995, 24.

30 U.S. Department of Energy, Ind. Technol. Progr. Energy Effic. Renew. Energy, 2007, 150.

31 Arpal Asociacion para el Reciclado de Aluminio.

32 E. G. de Araújo and J. A. S. Tenório, Mater. Sci. Forum, 2005, 498-499, 198204.

33 European Aluminium Foil Association, Did you know? - EAFA - The home of aluminium foil.

34 J. Payá, J. Monzó and M. V. Borrachero, Cem. Concr. Res., 1999, 29, 17731779.

35 J. C. B. Moraes, M. M. Tashima, J. L. Akasaki, J. L. P. Melges, J. Monzó, M. V. Borrachero, L. Soriano and J. Payá, Constr. Build. Mater., 2016, 124, 148-154.

36 E. Muthu Kumar and K. Ramamurthy, Constr. Build. Mater., 2017, 156, 11371149.

37 J. Payá, M. V. Borrachero, J. Monzó and L. Soriano, Mater. Construcción, 2009, 
59, 37-52.

579

580

581

582

583

584

585

586

587

588

589

590

591

592

38 ASTM International, ASTM D5334 - 14 Standard Test Method for Determination of Thermal Conductivity of Soil and Soft Rock by Thermal Needle Probe Procedure.

39 IEEE 442-1981 - IEEE Guide for Soil Thermal Resistivity Measurements.

40 S. Eggleston, L. Buendia, K. Miwa, T. Ngara and K. Tanabe, 2006 IPCC Guidel. Natl. Greenh. Gas Invent., 2006, 6.

41 A. J. Hamad, Int. J. Mater. Sci. Eng., 2014, 2, 152-157.

42 E. K. K. Nambiar and K. Ramamurthy, Cem. Concr. Res., 2007, 37, 221-230.

43 a Mellado, C. Catalán, N. Bouzón, M. V Borrachero, J. M. Monzó and J. Payá, RSC Adv., 2014, 4, 23846-23852.

44 M. Torres-Carrasco, C. Rodríguez-Puertas, M. Del Mar Alonso and F. Puertas, Bol. la Soc. Esp. Ceram. y Vidr., 2015, 54, 45-57.

45 S. Ministerio de Industria, Energía y Turismo, Secretaría de Estado de Energía, Madrid, IDAE 2011, http://www.idae.es/, (accessed 12 March 2018). 